\title{
Nutritional Ketosis Condition and Specific Ketogenic Diet, May Benefit Cancer Patients as an Alternative Treatment by Sudden Change in the Metabolic State of Cancer Cells
}

\section{Niknamian $S^{*}$}

*Biology Student at Islamic Azad University, Central Tehran Branch (IAUCTB), Iran

*Corresponding author: Soroush Niknamian, Biology Student at Islamic Azad

\section{Research Article}

Volume 1 Issue 1

Received Date: November 08, 2016

Published Date: November 15, 2016

University, Central Tehran Branch (IAUCTB), Member of Weston A. Price Foundation, Iran, E-mail: saina.monthly@gmail.com

\section{Abstract}

Cancer disease is the second cause of death in the United States and world-wide. Most Researchers estimate that 595,690 of American people will die from cancer at the end of the year 2017. That means 1,600 deaths/day approximately [1]. Cancer in modern societies is commonly treated with the combination of organ surgery, chemotherapy and radiotherapy. Many kinds of diet strategies have been experimented. However, none of them have been particularly effective. Interestingly, there is some applied research suggesting that a very low-carb ketogenic diet may help [2-4]. According to Otto Warburg hypothesis, the cause of cancer is the change in the metabolism of mitochondrion in human cells. Low oxygen in tissues in combination with high blood glucose will change the cell respiration from aerobic to anaerobic which leads to fermentation type of respiration. In this perspective and prospective research, I have shown the very low carbohydrate ketogenic diet and mostly ketosis, may benefit cancer patients in reducing and weakening cancer cells. Although further researches are needed, this perspective article could be beneficial in future perspective of alternative treatments of cancer.

Keywords: Cancer; Ketogenic diet; Ketosis; Warburg hypothesis; Blood sugar

\section{Introduction}

\section{Ketosis}

Ketosis is a metabolic condition in which ketone bodies are the supply of energy in the blood. In contrast to a condition of glycolysis, in which blood glucose provides most of the energy. In nutritional process of ketosis, the serum concentration of ketone bodies go over $0.5 \mathrm{mM}$ in blood and with low and stable levels of insulin and blood glucose [5,6]. It is almost always generalized with hyperketonemia, that is, an elevated level of ketone bodies in the blood throughout the body. Ketone bodies 


\section{International Journal of Biochemistry \& Physiology}

are formed by ketogenesis when liver glycogen stores are depleted or from metabolising medium-chain triglycerides [7]. The main ketone bodies used for energy are acetoacetate and $\beta$-hydroxybutyrate [8], and the levels of ketone bodies are regulated mainly by insulin and glucagon [9]. Most cells in the body can use both glucose and ketone bodies for fuel, and during ketosis, free fatty acids and glucose synthesis which is called gluconeogenesis, fuel the remainder.

Longer-term ketosis may be the result of staying on a very low-carbohydrate diet, and deliberately induced ketosis serves as a medical intervention for various conditions, such as intractable epilepsy, and the various types of diabetes [10]. In glycolysis, high levels of the hormone insulin promote the storage of body fat and block release of fat from adipose tissues, but in ketosis, fat reserves are released and consumed for energy $[9,11]$. Therefore, ketosis is sometimes referred to as the body's fat burning mode [5].

\section{Ketoacidosis}

Ketone bodies are acidic compounds, but acid-base homeostasis in the blood is normally maintained through bicarbonate buffering and respiratory compensation to vary the amount of $\mathrm{CO}_{2}$ in the bloodstream, hydrogen ion absorption by tissue proteins and bones and renal compensation through increased excretion of dihydrogen phosphate and ammonium ions [12]. Excess of ketone bodies can disrupt normal compensatory mechanisms and lead to acidosis if blood $\mathrm{pH}$ falls below 7.35. So the level of $\mathrm{PH}$ in the blood is very important in the ketogenic diet to remain slightly alkaline. A mild acidosis may be the result of prolonged fasting, following a district ketogenic diet or a very low calorie diet $[12,13]$.

Fats are stored in adipose tissue released from the fat cells into the blood as free fatty acids and glycerol when insulin levels are very low and glucagon and epinephrine levels in the blood are high. This condition happens between meals, during fasting, starvation and strenuous exercise, when blood glucose levels are likely to fall. Fatty acids are very high energy fuels, and are taken up by all metabolizing cells which have mitochondria. Fatty acids can only be metabolized in the mitochondria. Red blood cells do not contain mitochondrion and are therefore entirely dependent on glycolysis for their energy requirements. In all other tissues the fatty acids that enter the metabolizing cells are combined with co-enzyme A to form acyl-CoA chains. These are transferred and sent into the mitochondria of the cells, where they are broken down into acetyl-CoA units by a sequence of reactions known as $\beta$-oxidation [14].

The acetyl-CoA produced by $\beta$-oxidation enters the citric acid cycle in the mitochondrion by combining with oxaloacetate to form citrate. This results in the complete combustion of the acetyl-CoA to $\mathrm{CO}_{2}$ and water. The energy released in this process is captured in the form of 1 GTP and 11 ATP molecules per acetyl-CoA molecule oxidized $[15,16]$. This is the fate of acetyl-CoA wherever $\beta$-oxidation of fatty acids happens, except under certain conditions in the liver. In the liver, oxaloacetate is wholly or partially diverted into the gluconeogenic pathway during fasting, starvation, a low carbohydrate diet, prolonged strenuous exercise, and in uncontrolled type 1 diabetes mellitus. Under these circumstances oxaloacetate is hydrogenated to malate which is removed from the mitochondrion to be converted into glucose in the cytoplasm of the liver cells, from where it is released into the blood [15]. In the liver, therefore, oxaloacetate is unavailable for condensation with acetyl-CoA when significant gluconeogenesis has been stimulated by low or absence of insulin and high glucagon concentrations in the blood. Under these circumstances, acetyl-CoA is diverted to the formation of acetoacetate and betahydroxy-butyrate [15].

Acetoacetate, beta-hydroxybutyrate and their breakdown product, acetone, are confusingly known as ketone bodies as they are not bodies at all, but watersoluble chemical substances. The ketone bodies are released by the liver into the blood. All cells with mitochondria can take ketone bodies up from the blood and reconvert them into acetyl-CoA, which can then be used as fuel in their citric acid cycles, as no other tissue can divert its oxaloacetate into the gluconeogenic pathway in the way that the liver does this. Unlike free fatty acids, ketone bodies can cross the blood-brain barrier and are therefore available as fuel for the cells of the central nervous system, acting as a substitute for glucose, on which these cells normally survive [17]. The occurrence of high levels of ketone bodies in the blood during a low carbohydrate diet is known as ketosis, and in its extreme form, as ketoacidosis.

When the body is in ketosis, one's breath may smell of acetone. This is due to the breakdown of acetoacetic acid into acetone and carbon dioxide which is exhaled through the lungs. 


\section{International Journal of Biochemistry \& Physiology}

\begin{tabular}{|c|c|c|c|}
\hline \multirow{2}{*}{$\begin{array}{l}\text { Urine } \\
\text { value }\end{array}$} & \multirow[t]{2}{*}{ Designation } & \multicolumn{2}{|c|}{$\begin{array}{l}\text { Approximate serum } \\
\text { concentration }\end{array}$} \\
\hline & & $\mathrm{mg} / \mathrm{dL}$ & $\mathrm{mmol} / \mathrm{l}$ \\
\hline 0 & Negative & $\begin{array}{c}\text { Reference } \\
\text { range: } 0.5-3.0\end{array}$ & $\begin{array}{c}0.05- \\
0.29\end{array}$ \\
\hline $1+$ & & $\begin{array}{l}5 \text { (interquartile } \\
\text { range (IQR): 1- } \\
9 \text { ) }\end{array}$ & $\begin{array}{c}0.5 \text { (IQR: } \\
0.1-0.9 \text { ) }\end{array}$ \\
\hline $2+$ & Ketonuria & 7 (IQR: 2-19) & $\begin{array}{l}0.7 \text { (IQR: } \\
0.2-1.8)\end{array}$ \\
\hline $3+$ & & 30 (IQR: 14-54) & $\begin{array}{l}3 \text { (IQR: } \\
1.4-5.2)\end{array}$ \\
\hline $4+$ & $\begin{array}{c}\text { Severe } \\
\text { ketonuria }\end{array}$ & - & - \\
\hline
\end{tabular}

Table 1: Urine test for ketosis and ketoacidosis [18-22].

The concentration of ketone bodies may vary depending on diet, exercise, degree of metabolic adaptation and genetic factors. Ketosis can be induced when a ketogenic diet is followed for more than 3 days. This induced nutritional ketosis [23].

\begin{tabular}{|c|c|}
\hline $\begin{array}{c}\text { Blood concentration } \\
\text { (m.molar) }\end{array}$ & Condition \\
\hline$<0.2$ & not in ketosis \\
\hline $0.2-0.5$ & slight/mild ketosis \\
\hline $0.5-3.0$ & $\begin{array}{c}\text { induced/nutritional } \\
\text { ketosis }\end{array}$ \\
\hline $2.5-3.5$ & post-exercise ketosis \\
\hline $3.0-6.0$ & starvation ketosis \\
\hline $15-25$ & ketoacidosis \\
\hline
\end{tabular}

Table 2: Demonstrates the ketone concentrations seen under various conditions: [5] Blood concentration of ketone bodies and the condition.

\section{Materials and Methods}

Warburg effect should be mentioned firstly as a cause of cancer and then I go through the studies which prove the accuracy of Warburg hypothesis and effectiveness of ketogenic diet which is a very low carbohydrate diet in reducing the blood glucose which fuels the cancer cells to respire and divide.

\section{Warburg effect}

Oncologically, the Warburg effect explains that cancer cells produce energy by a high rate of glycolysis followed by lactic acid fermentation in the cytosol $[24,17]$, rather than by a comparatively low rate of glycolysis followed by oxidation of pyruvate in mitochondria as in normal cells. The latter process is aerobic which uses oxygen. Rapidly growing tumor cells have glycolytic rates up to 200 times higher than normal tissues of origin, this occurs even if oxygen is plentiful [25-27].

The Warburg effect is a consequence of damage to the mitochondria in cancer, or an adaptation to low-oxygen environments within tumors, or a result of cancer genes shutting down the mitochondria because they are involved in the cell's apoptosis program which would normally kill cancerous cells. It may also be an effect associated with cell proliferation. Because glycolysis provides most of the building blocks required for cell proliferation, cancer and normal proliferating cells have been proposed to need to activate glycolysis, despite the presence of oxygen, to proliferate [28]. Evidence attributes some of the high aerobic glycolytic rates to an over-expressed form of mitochondrial-bound hexokinase [29] responsible for driving the high glycolytic activity. In kidney cancer, this effect could be simply because of the presence of mutations in the von Hippel-Lindau tumor suppressor gene upregulating glycolytic enzymes, including the M2 splice isoform of pyruvate kinase [30].

Lewis C. Cantley in March 2008 concluded that the tumor M2-PK which is a form of the pyruvate kinaseenzyme, gives rise to the Warburg effect. Tumor $\mathrm{M} 2-\mathrm{PK}$ is produced in all rapidly dividing cells, and is responsible for enabling cancer cells to consume glucose at an accelerated rate, on forcing the cells to switch to pyruvate kinase's alternative form by inhibiting the production of tumor M2-PK, their growth was curbed. The researchers acknowledged the fact that the exact chemistry of glucose metabolism was likely to vary across different forms of cancer, therefore, PKM2 was identified in all of the cancer cells they had tested. This enzyme form is not usually found in healthy tissue, though it is apparently necessary when cells need to multiply quickly, that is in healing wounds or hematopoiesis $[31,32]$.

Many substances have been developed which inhibit glycolysis [33], including SB-204990, 2-deoxy-D-glucose, 3-bromopyruvate, 3-BrOP, 5-thioglucose and dichloroacetic acid [34].

Alpha-cyano-4-hydroxycinnamic acid, which is a smallmolecule inhibitor of monocarboxylate transporters which prevent lactic acid build up in tumors, has been 


\section{International Journal of Biochemistry \& Physiology}

successfully used as a metabolic target in brain tumor pre-clinical research [35-38].

Dichloroacetic acid, which is a small-molecule inhibitor of mitochondrial pyruvate dehydrogenase kinase, downregulates glycolysis in vitro and in vivo $[39,40]$.

As a matter of fact, High blood glucose levels accelerate cancer cell proliferation in vitro, while glucose deprivation has led to apoptosis. These findings have initiated further study of the effects of carbohydrate restriction on tumor growth. Several clinical evidences show that lower blood glucose levels in late-stage cancer patients have been correlated with better outcomes [41].

\section{Ketogenic Diet}

Ketogenic diet is a kind of regime which uses high fat content and low carbohydrate. This diet changes the metabolic state into the condition called Ketosis. After several days, fat becomes your body's primary energy source which causes an increase in the levels of compounds which is called "ketones" in the blood [42]. In general, a ketogenic diet used for weight loss is about $60-75 \%$ of calories as fat, with $15-30 \%$ of calories from protein and $5-10 \%$ of calories from carbs. However, when a ketogenic diet is being used therapeutically for the treatment of cancer, the fat content may be significantly higher that is up to $90 \%$ of calories, and the protein content lower [43].

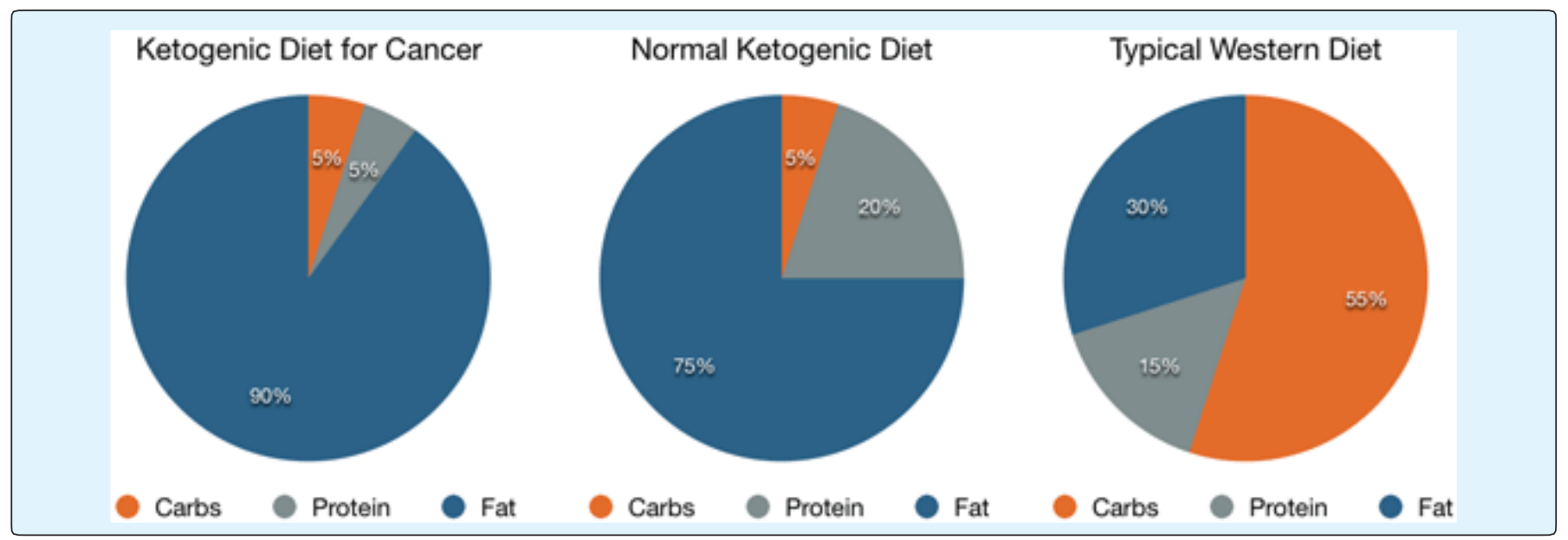

\section{Blood Sugar and Cancer}

Most cancer treatment strategies are aimed to target the biological differences between cancer cells and normal cells. All cancer cells uses carbohydrate as their energy source to multiply. The ketogenic diet changes the metabolic state of the cancer cells in which they do not have their energy source, so the blood sugar goes down dramatically $[2,3,44]$.

The aim of the ketogenic diet is starving cancer cells of their fuel which is glucose and sugar. The long-term effect of this diet which starves the cells, may be that the cancer cells will grow more slowly, decrease in size or even die. It seems possible that a ketogenic diet could help reduce the progression of cancer because it causes a rapid decrease in blood sugar levels [2-4].

\section{Ketogenic Diet and Cancer Treatment}

There are several other mechanisms that may explain how a ketogenic diet can aid in cancer treatment. Firstly, eliminating carbs can quickly lower calorie intake, reducing the energy available to the cells in your body. In turn, this may slow down tumor growth and the cancer's progression. Insulin is an anabolic hormone. That means when it is present in the blood, it makes the growth of cancer cells. Therefore, lower insulin or blood glucose, may slow tumor growth $[45,46]$.

Cancer cells cannot use ketones as fuel. Research shows that ketones may reduce tumor size and growth [47].

\section{Ketogenic Diet and Cancer in Animals}

Researchers have tested the ketogenic diet as an alternative cancer treatment for more than 50 years and most of these studies were done in animals. A large number of these animal studies have demonstrated that ketogenic diet can reduce tumor growth and improve survival rates [48-51].

One 22-day study in mice looked at the differences between the effects of ketogenic and other diets in 


\section{International Journal of Biochemistry \& Physiology}

treatment of cancer. Interestingly, the researchers found that $60 \%$ of mice on a ketogenic diet survived. This increased to $100 \%$ in mice that got a ketone supplement in addition to the ketogenic diet. However, none of the mice survived on a regular diet or better told a diet contained carbohydrates [48].
Another study in mice tested a ketogenic diet with or without oxygen therapy. The result is shown in picture below: [49]

\section{Tumor Size in Mice Before and After Treatment}

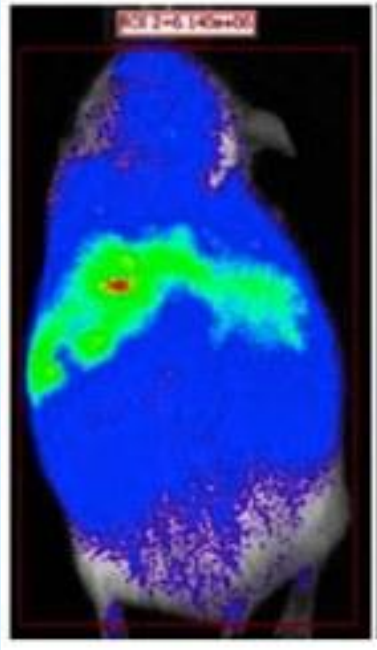

Normal Diet

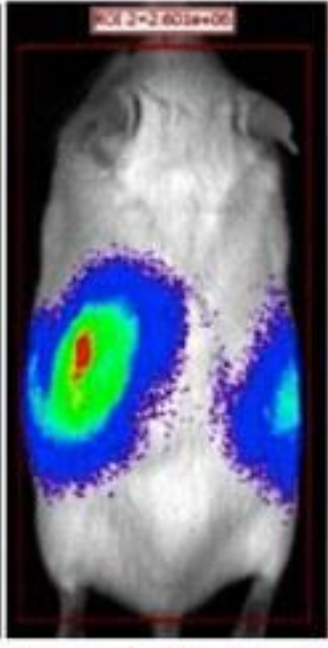

Normal Diet Combined with Oxygen Therapy

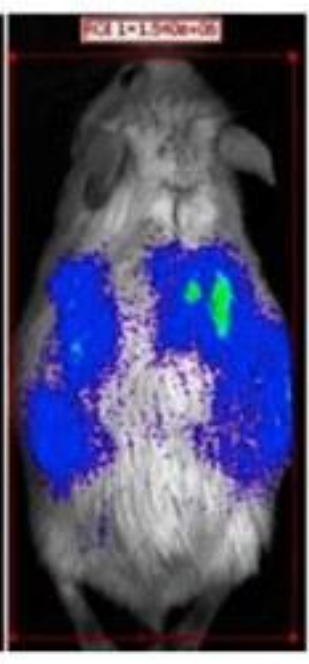

Ketogenic Diet

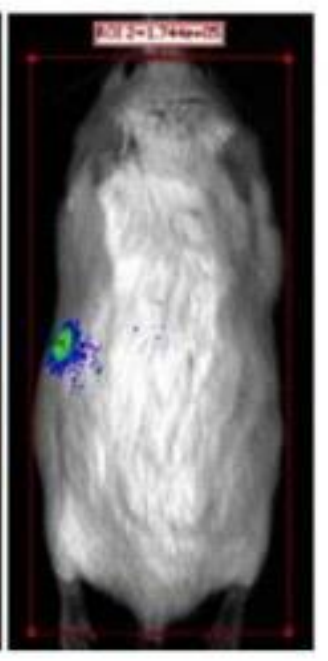

Bioluminescence (Photons/sec)

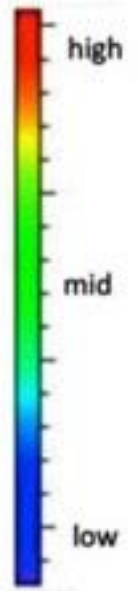

Ketogenic Diet Combined with Oxygen Therapy
The result is obvious. A ketogenic diet increased survival time by $56 \%$. This number increased to $78 \%$ when combined with oxygen therapy. These results prove that cancer cells starve in the lack of glucose and in high amounts of oxygen in blood [49].

\section{Ketogenic Diet and Cancer in Humans}

Presently, limited researches do seem to show that a ketogenic diet may reduce tumor size and rate of progression in certain cancers. One of the few documented published case studies was performed on a 65-year-old woman with brain cancer. Following surgery, she received a ketogenic diet. Meanwhile, the tumor's progression slowed. But, 10 weeks after returning to a normal diet, she experienced a significant increase in tumor growth [52].

Similar case reports examined the reactions to a ketogenic diet in two young girls who were undergoing treatment for advanced brain cancer. Researchers observed that glucose uptake was decreased in the tumors of both patients. One of the girls reported that her quality of life had improved and remained on the diet for 12 months. During that time her cancer showed no further progression [53].

One study monitored tumor growth in response to a high-carb versus a ketogenic diet in 27 patients with cancer of the digestive tract.Tumor growth increased by $32.2 \%$ in patients who received the high-carb diet, but decreased by $24.3 \%$ in the patients on the ketogenic diet $[54,55]$.

In another study, three out of five patients on a ketogenic diet combined with radiation or chemotherapy experienced complete treatment. More interesting, the other two participants found the disease progressed after they stopped the ketogenic diet [56].

\section{Discussions}

\section{Cellular respiration}

Cellular respiration is a process of metabolic reactions that happens in the cells of organisms to convert 


\section{International Journal of Biochemistry \& Physiology}

biochemical energy from nutrients into adenosine triphosphate (ATP), and then release waste products. These reactions in respiration are catabolic reactions, which break large molecules into smaller ones, releasing energy in the process, as weak so-called "high-energy" bonds are replaced by stronger bonds in the products. Respiration is one of the key ways a cell releases chemical energy to fuel cellular activity. Cellular respiration is considered an exothermicredox reaction which releases heat. The overall reaction occurs in a series of biochemical steps, most of which are redox reactions themselves. Although cellular respiration is a combustion reaction, it clearly does not resemble one when it occurs in a living cell because of the slow release of energy from the series of reactions. Nutrients that are commonly used by animal and plant cells in respiration include sugar, amino acids and fatty acids, and the most common electron acceptor is molecular oxygen. The chemical energy stored in ATP can be used to drive processes requiring energy [57].
Cellular respirations can be put into two groups:

\section{Aerobic respiration}

Aerobic respiration needs oxygen for creating ATP. Although carbohydrates, fats, and proteins are consumed as reactants, it is the preferred method of pyruvate breakdown in glycolysis and requires that pyruvate enter the mitochondria in order to be fully oxidized by the Krebs cycle. The products of this process are carbon dioxide and water, however, the energy transferred is used to break bonds in ADP as the third phosphate group is added to form ATP (adenosine triphosphate), by substrate-level phosphorylation, $\mathrm{NADH}$ and $\mathrm{FADH}_{2}$

\begin{tabular}{||c|c|}
\hline \multirow{3}{*}{$\begin{array}{c}\text { Simplified } \\
\text { reaction }\end{array}$} & $\begin{array}{c}\mathrm{C}_{6} \mathrm{H}_{12} \mathrm{O}_{6}(\mathrm{~s})+6 \mathrm{O}_{2}(\mathrm{~g}) \rightarrow 6 \mathrm{CO}_{2}(\mathrm{~g})+6 \\
\mathrm{H}_{2} \mathrm{O}(\mathrm{l})+\text { heat }\end{array}$ \\
\cline { 2 - 2 } & $\Delta \mathrm{G}=-2880 \mathrm{~kJ}$ per mol of $\mathrm{C}_{6} \mathrm{H}_{12} \mathrm{O}_{6}$ \\
\hline
\end{tabular}

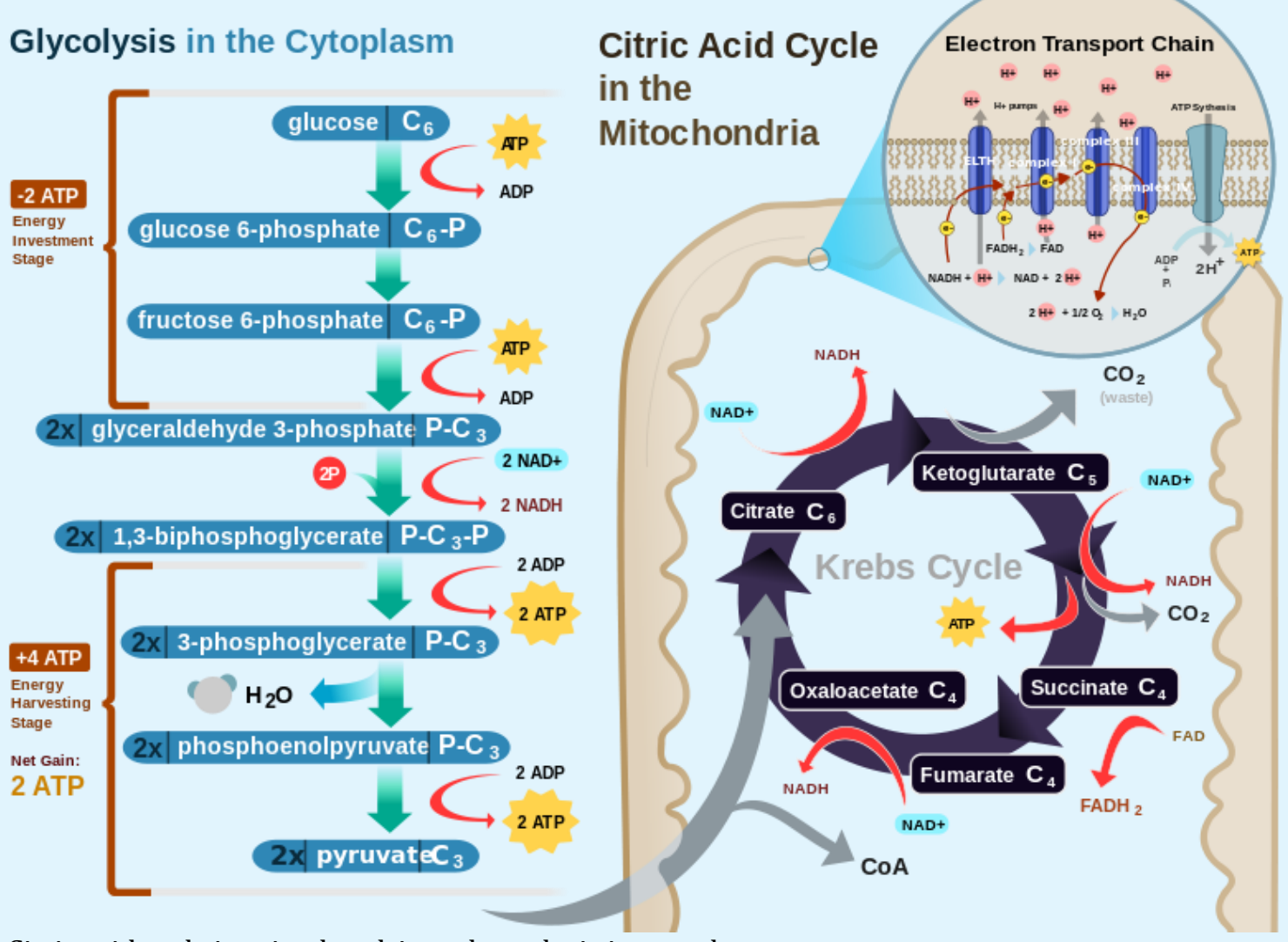

Figure 3: Citric acid cycle in mitochondria and gycolysis in cytoplasm.

Most of the ATP produced by aerobic cellular respiration is made by oxidative phosphorylation. This works by the energy released in the consumption of pyruvate being used to create a chemiosmotic potential by pumping protons across a membrane. This potential is then used to drive ATP synthase and produce ATP from 


\section{International Journal of Biochemistry \& Physiology}

ADP and a phosphate group. Biology textbooks often state that 38 ATP molecules can be made per oxidized glucose molecule during cellular respiration, 2 from glycolysis, 2 from the Krebs cycle, and about 34 from the electron transport system. But, this maximum result is never reached because of the losses due to leaky membranes and the cost of moving pyruvate and ADP into the mitochondrial matrix as well, and current estimates range around 29 to 30 ATP per glucose [58].

Glycolysis is a metabolic pathway that takes place in the cytosol of cells in all living organisms. This pathway can function with or without the presence of oxygen. In humans, aerobic conditions produce pyruvate and anaerobic conditions produce lactate. In aerobic conditions, the process converts one molecule of glucose into two molecules of pyruvate, generating energy in the form of two net molecules of ATP. Four molecules of ATP per glucose are actually produced; however, two are consumed as part of the preparatory phase. The initial phosphorylation of glucose is required to increase the reactivity which is the decrease in its stability in order for the molecule to be cleaved into two pyruvate molecules by the enzyme aldolase. During the pay-off phase of glycolysis, four phosphate groups are changed into ADP by substrate-level phosphorylation to make four ATP, and two NADH are produced when the pyruvate are oxidized: [59]

Glucose $+2 \mathrm{NAD}^{+}+2 \mathrm{P}_{\mathrm{i}}+2 \mathrm{ADP} \rightarrow 2$ pyruvate $+2 \mathrm{NADH}+$ $2 \mathrm{ATP}+2 \mathrm{H}^{+}+2 \mathrm{H}_{2} \mathrm{O}+$ heat

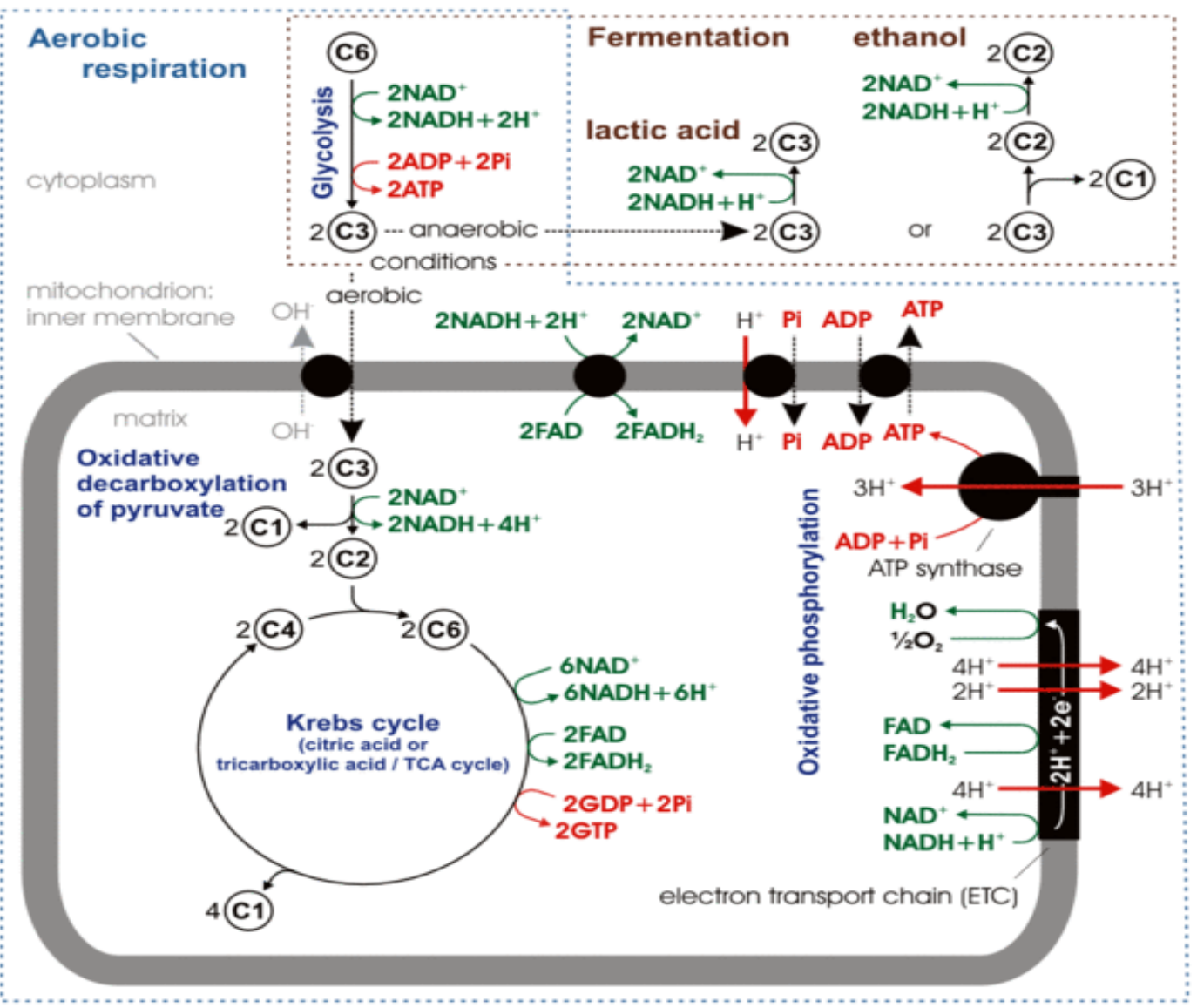

Figure 4: Aerobic respiration using Krebs cycle versus fermentation in a cell.

Pyruvate is oxidized to acetyl-CoA and $\mathrm{CO}_{2}$ by the pyruvate dehydrogenase complex or PDC. The PDC contains several copies of three enzymes and is placed in the mitochondria of eukaryotic cells and in the cytosol of prokaryotes. In the conversion of pyruvate to acetyl-CoA, one molecule of $\mathrm{NADH}$ and one molecule of $\mathrm{CO}_{2}$ are formed. 


\section{International Journal of Biochemistry \& Physiology}

When oxygen is present, acetyl-CoA is produced from the pyruvate molecules created in glycolysis process. When oxygen is present, the mitochondria will go through aerobic respiration that leads to the Krebs cycle. But, if oxygen is not present or in Otto Warburg hypothesis it goes under $30 \%$ of normal oxygen, fermentation of the pyruvate molecule will occur. In the presence of oxygen, when acetyl-CoA is produced, the molecule then enters the Krebs cycle inside the mitochondrion, and is oxidized to $\mathrm{CO}_{2}$, while at the same time reducing NAD to NADH. $\mathrm{NADH}$ can be used by the electron transport chain to create further ATP as part of oxidative phosphorylation. To fully oxidize the equivalent of one glucose molecule, two acetyl-CoA must be metabolized by the Krebs cycle. Therefore, $\mathrm{H}_{2} \mathrm{O}$ and $\mathrm{CO}_{2}$ are created during this cycle. The Krebs cycle is an 8-step process involving different enzymes and co-enzymes. During the cycle, acetyl-CoA + oxaloacetate results citrate, which is rearranged to a more reactive form named isocitrate. Isocitrate then is modified to become $\alpha$-ketoglutarate, succinyl-CoA, succinate, fumarate, malate, and, finally, oxaloacetate. The net outcome of high-energy compounds from one cycle is 3 $\mathrm{NADH}, 1 \mathrm{FADH}_{2}$, and $1 \mathrm{GTP}$. The GTP may subsequently be used to yield ATP. Therefore, the total result from one glucose molecule is $6 \mathrm{NADH}, 2 \mathrm{FADH}_{2}$ and two ATP molecules.

In eukaryotes, oxidative phosphorylation occurs in the mitochondrial cristae. It comprises the electron transport chain that establishes a proton gradient across the boundary of inner membrane by oxidizing the NADH which is produced from the Krebs cycle. ATP is synthesized by the ATP synthase enzyme. The electrons are finally transferred to exogenous oxygen and with the addition of 2 protons, water is formed.

\begin{tabular}{|c|c|c|c|}
\hline Level & coenzyme & ATP & Source of ATP \\
\hline $\begin{array}{c}\text { Glycolysis preparatory } \\
\text { phase }\end{array}$ & & -2 & $\begin{array}{c}\text { Phosphorylation of glucose and fructose 6-phosphate uses two } \\
\text { ATP from the cytoplasm. }\end{array}$ \\
\hline \multirow{2}{*}{\begin{tabular}{c} 
Glycolysis pay-off phase \\
\cline { 2 - 4 }
\end{tabular}} & $2 \mathrm{NADH}$ & 3 or 5 & $\begin{array}{c}\text { Oxidative phosphorylation : Each NADH produces net 1.5 ATP } \\
\text { (instead of usual 2.5) due to NADH transport over the } \\
\text { mitochondrial membrane }\end{array}$ \\
\hline $\begin{array}{c}\text { Oxidative } \\
\text { decarboxylation of } \\
\text { pyruvate }\end{array}$ & $2 \mathrm{NADH}$ & 5 & Oxidative phosphorylation \\
\hline \multirow{2}{*}{\begin{tabular}{c} 
Krebs cycle \\
\cline { 2 - 4 }
\end{tabular}} & $6 \mathrm{NADH}$ & 15 & Substrate-level phosphorylation \\
\cline { 2 - 4 } & $2 \mathrm{FADH} 2$ & 3 & Oxidative phosphorylation \\
\hline \multicolumn{2}{|c|}{ Total Outcome of ATP } & $\begin{array}{c}30 \text { to } \\
32 \mathrm{ATP}\end{array}$ & $\begin{array}{c}\text { From the complete oxidation of one glucose molecule to carbon } \\
\text { dioxide and oxidation of all the reduced coenzymes. }\end{array}$ \\
\hline
\end{tabular}

Although it is theoretical yield of 38 ATP molecules per glucose during cellular respiration, these conditions are generally not understood, since losses such as the cost of moving pyruvate, phosphate and ADP into the mitochondria. All are actively transported using carriers that utilize the stored energy in the proton electrochemical gradient.

The outcome of these transport processes using the proton electrochemical gradient is that more than $3 \mathrm{H}^{+}$ are needed to make 1 ATP. Obviously this reduces the theoretical efficiency of the whole process and the likely maximum is closer to 28-30 ATP molecules [58]. In practice, the efficiency may be even lower because the inner membrane of the mitochondria is slightly leaky to protons. Other factors may also dissipate the proton gradient creating apparently leaky mitochondria. An uncoupling protein known as thermogenin is expressed in some cell types and is a channel that can transport protons. When this protein is active in the inner membrane it short circuits the coupling between the electron transport chain and ATP synthesis. The potential energy from the proton gradient is not used to make ATP but generates heat. This is particularly important in brown fat thermogenesis of newborn and hibernating mammals [60].

Based on some newer sources, the ATP outcome during aerobic respiration is not 36 to 38 , but only about 30 to 32 ATP molecules / 1 molecule of glucose. Therefore 


\section{International Journal of Biochemistry \& Physiology}

altogether this gives $4+3$ (or 5 ) $+20+3=30$ or 32 ATP per molecule of glucose [61].

\section{Fermentation}

Without or due to lack of oxygen, pyruvate as pyruvic acid is not metabolized by cellular respiration, therefore goes through a process of fermentation. The pyruvate is not transported into the mitochondrion, but remains in the cytoplasm, where it is converted to waste products that may be removed from the cell. In the absence of oxygen, fermentation prevents the buildup of NADH in the cytoplasm and provides NAD+ for glycolysis. This waste product varies depending on the organism. In skeletal muscles, the waste product is lactic acid. This type of fermentation is called lactic acid fermentation. In strenuous exercise, when energy demands exceed energy supply, the respiratory chain cannot process all of the hydrogen atoms joined by NADH. During anaerobic glycolysis, NAD+ regenerates when pairs of hydrogen combine with pyruvate to form lactate. Lactate formation is catalyzed by lactate dehydrogenase in a reversible reaction. Lactate can also be used as an indirect precursor for liver glycogen. During recovery, when oxygen becomes available, NAD+ attaches to hydrogen from lactate to form ATP. In yeast, the waste products are ethanol and carbon dioxide. This type of fermentation is known as alcoholic or ethanol fermentation. The ATP generated in this process is made by substrate-level phosphorylation, which does not require oxygen.

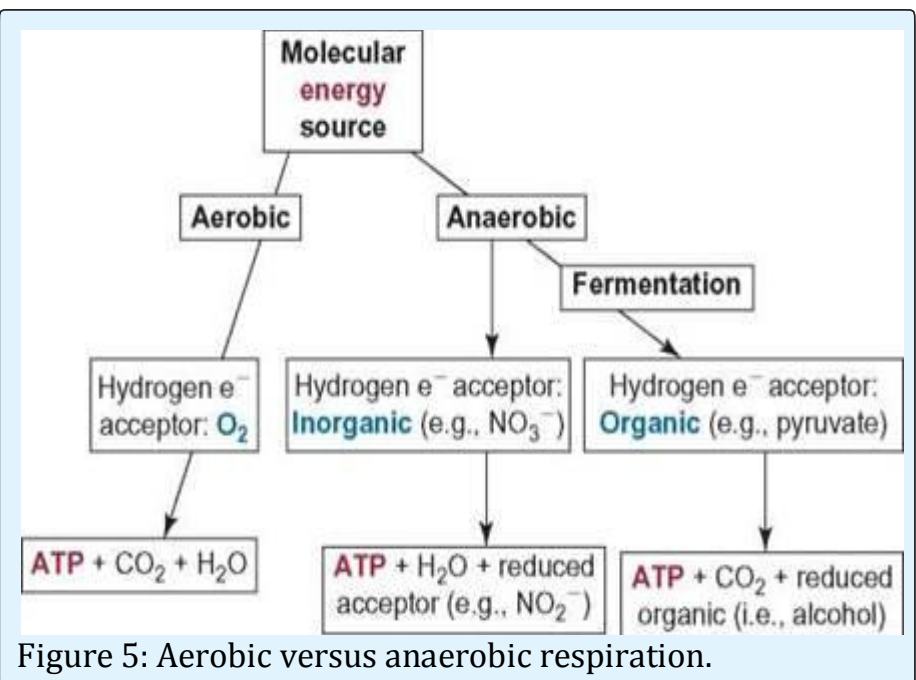

Fermentation is less efficient at using the energy from glucose. This means only two ATP molecules are produced per glucose, compared to the 38 ATP per glucose nominally produced by aerobic respiration. This is because the waste products of fermentation still contain chemical potential energy that can be released by oxidation. For prokaryotes to continue a rapid growth rate when they are shifted from an aerobic environment to an anaerobic environment, they must increase the rate of the glycolytic reactions.

\section{Introduction to Evolutionary Cell Memory Hypothesis (ECM)}

According to Otto Warburg hypothesis of cancer, when the amount of oxygen goes down nearly under $30 \%$ of normal oxygen in tissue cells and the glucose amounts in blood are enough, normal cells may become cancer cells which uses fermentation respiration [62].

Shifting the respiration mechanism in eukaryotic cells which includes mitochondrion metabolism raises a provocative thought. As nearly all scientists agree with the endosymbiosis theory of mitochondrion, these energy producing machines in human cells were a form of bacterium in earlier life. Therefore, going through all phases of this perspective research article, I propose a hypothesis called The Evolutionary Cell Memory (ECM) hypothesis which explains these types and changes in human cells to cancer cells.

Based on ECM hypothesis, mitochondrion in eukaryotic cells does have their primitive genes in earlier life and these genes explain the weird shift from normal cell to cancer cell based on Warburg Effect.

ECM hypothesis says that: "When the habitat of a microorganism which includes mitochondrion changes dramatically, the mitochondrion metabolism (or respiration process) changes to the way it was in the earlier simple life form (bacterium in water world theory) to saving its life from distinction.

In human cells, when the amount of oxygen goes down under $30 \%$ of normal oxygen needed for the cell to respire normally, mitochondrion changes the aerobic estate of respiration to anaerobic fermentation estate in order to save the life of the cell and continue the energy production for the tissue. This shift is amazing due to the ability of mitochondrion to change its shape into the earlier form in evolution of mitochondria. By this sudden shift, the cell will not distinct and multiply faster just like bacterium in the earlier form of life. 


\section{International Journal of Biochemistry \& Physiology}

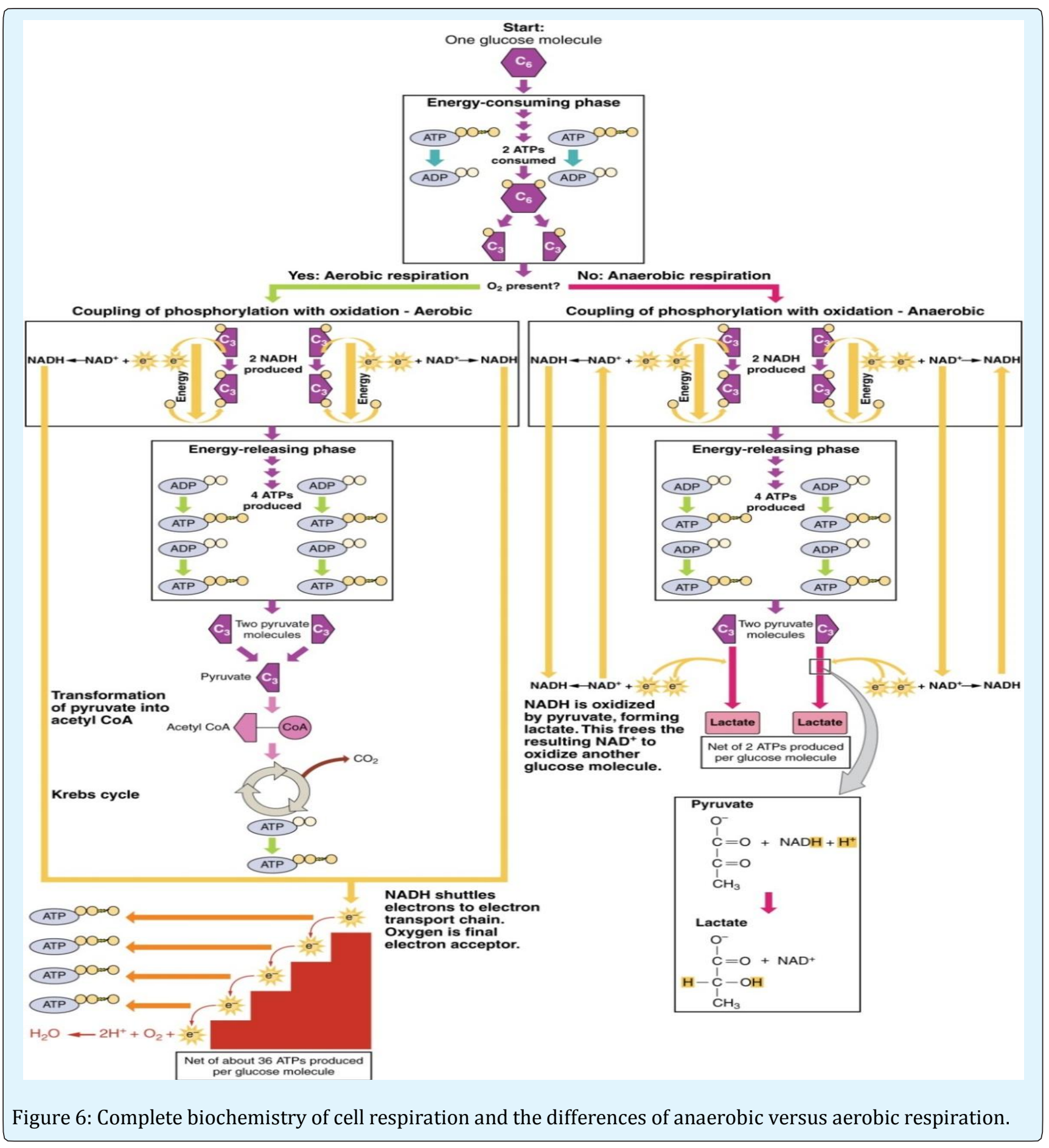

Niknamian S. Nutritional Ketosis Condition and Specific Ketogenic Diet, May 


\section{International Journal of Biochemistry \& Physiology}

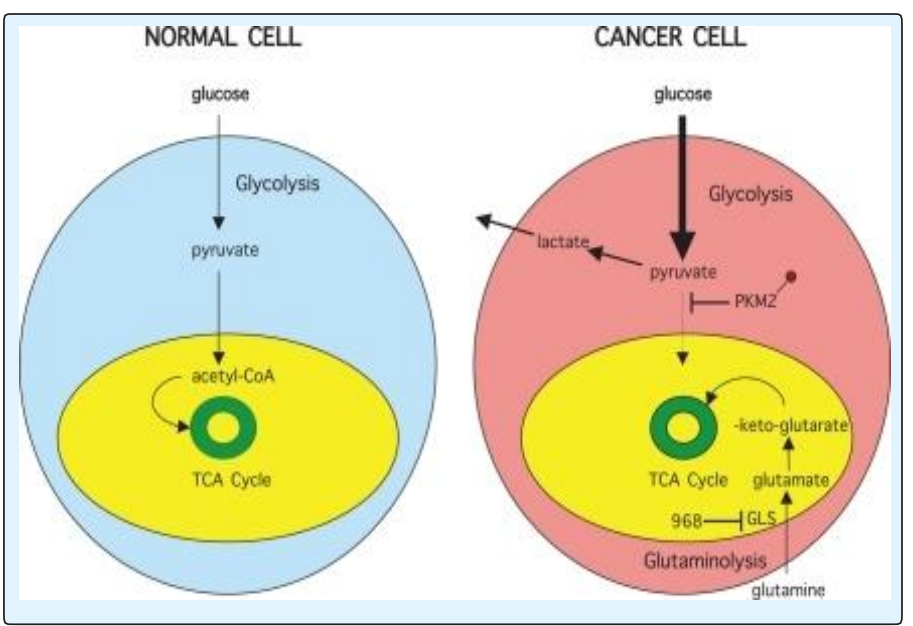

\section{Acknowledgement}

I would like to thank miss SoraNiknamian for her special help in preparing this research, and thank specially to Mrs. Sally Fallon Morell the president of Weston A. Price Foundation(WAPF) for her help and support informationally, and Professor Thomas Seyfried for his inspirational and informative help.

\section{Conclusion}

The ketogenic diet is a very low carbohydrate, highfat diet. For cancer treatment, fat intake may be as high as $90 \%$ of total calorie intake. There are also some mechanisms that suggest a ketogenic diet may help prevent the development of cancer in the first place. As a matter of fact, it may reduce several of the main risk factors for cancer. A few small studies and researches in humans suggest that a ketogenic diet may help slow the progression of cancer. But, more research is needed. Beyond lowering blood sugar, the ketogenic diets may also help treat cancer via other mechanisms. These include lowering calories, reducing insulin and increasing ketones. In animals, the ketogenic diet seems to be a promising alternative treatment for cancer. Ketogenic diet can lower blood sugar levels which in turn may help reduce tumor growth and even starve cancer cells of energy they use to respire.

\section{References}

1. Siegel RL, Miller KD, Jemal A (2016) Cancer statistics, 2016. CA Cancer J Clin 66(1): 7-30.

2. Bryan G Allen, Sudershan K Bhatia, Carryn M Anderson, Julie M Eichenberger-Gilmore, Zita A Sibenaller, et al. (2014) Ketogenic diets as an adjuvant cancer therapy: History and potential mechanism. Redox Biol 2: 963-970.

3. Branco AF, Ferreira A, Simões RF, Magalhães-Novais S, Zehowski C, et al. (2016) Ketogenic diets: from cancer to mitochondrial diseases and beyond. Eur J Clin Invest 46(3): 285-298.

4. A Paoli, A Rubini, J S Volek, K A Grimaldi (2013) Beyond weight loss: a review of the therapeutic uses of very-low-carbohydrate (ketogenic) diets. Eur J Clin Nutr. 67(8): 789-796.

5. Volek\&Phinney, page 91.

6. The American Heritage Medical Dictionary Copyright 2007. Mosby's Medical Dictionary, 8th edition. 2009. Dorland's Medical Dictionary for Health Consumers. 2007.

7. Bach A, Schirardin H, Weryha A, Bauer M (1977). Ketogenic response to medium-chain triglyceride load in the rat. J Nutr 107 (10): 1863-1870.

8. Champe, Pamela C.; Harvey, Richard A. Lippincott's Illustrated Reviews: Biochemistry. Lippincott Williams \& Wilkins.

9. Johnston DG, Pernet A, McCulloch A, Blesa-Malpica G, Burrin JM, Alberti KG (1982) Some hormonal influences on glucose and ketone body metabolism in normal human subjects. Ciba Foundation symposium 87: 168-191.

10. Kossoff Eric H, Freeman John M, Turner Zahava, Rubenstein James E (2011) Ketogenic Diets: Treatments for Epilepsy and Other Diseases. Demos Health.

11. Manninen Anssi H (2004) Metabolic Effects of the Very-Low-Carbohydrate Diets: Misunderstood "Villains" of Human Metabolism. J IntSoc Sports Nutr 1(2): 7-11.

12. Hartman AL, Vining EP (2007) Clinical aspects of the ketogenic diet. Epilepsia 48(1): 31-42.

13. Delbridge E, Proietto J (2006) State of the science: VLED (Very Low Energy Diet) for obesity. Asia Pac J ClinNutr 15: 49-54.

14. Volek Jeff S, Phinney Stephen D (2012) The Art and Science of Low Carbohydrate Performance. Beyond Obesity. P. 91. 


\section{International Journal of Biochemistry \& Physiology}

15. Stryer, Lubert (1995) Biochemistry. (Fourth ed.), W H Freeman and Company New York, pp. 510-515, 581$613,775-778$.

16. Lawrie RA, Ledward David (2014). Lawrie's Meat Science. Elsevier Science.

17. Alfarouk KO (2016) Tumor metabolism, cancer cell transporters, and microenvironmental resistance. Journal of Enzyme Inhib Med Chem 31(6):859-866.

18. PTS PANELS ${ }^{\mathrm{TM}}$ Ketone Test Strips Information paper PS-002588E Rev. 2 10/05 by Polymer Technology Systems.

19. Converted from molar values, using average of 10.3 $\mathrm{g} / \mathrm{mol}$ as used in: PTS PANELS ${ }^{\mathrm{TM}}$ Ketone Test Strips Information paper PS-002588E Rev. 2 10/05 by Polymer Technology Systems, and subsequently rounded to same number of significant figures as molar value.

20. Taboulet P, Deconinck N, Thurel A, Haas L, Manamani J, et al. (2007) Correlation between urine ketones (acetoacetate) and capillary blood ketones (3-betahydroxybutyrate) in hyperglycaemic patients. Diabetes Metab 33(2): 135-139.

21. Sekizawa A, Sugito $Y$, Iwasaki $M$, Watanabe A, Jimbo M, et al. (2001) Cell-free fetal DNA is increased in plasma of women with hyperemesis gravidarum. Clinical Chemistry. 47(12): 2164-2165.

22. Burbos N, Shiner AM, Morris E (2008) Severe metabolic acidosis as a consequence of acute starvation in pregnancy. Archives of Gynecology and Obstetrics. 279(3): 399-400.

23. Volek\&Phinney, page 302.

24. Alfarouk KO, Verduzco D, Rauch C, Muddathir AK, Adil $\mathrm{HH}$, et al. (2014) Glycolysis, tumor metabolism, cancer growth and dissemination. A new pH-based etiopathogenic perspective and therapeutic approach to an old cancer question. Oncoscience. 1(12): 777802.

25. Alfarouk KO, Muddathir AK, Shayoub ME (2011) Tumor acidity as evolutionary spite". Cancers 3(1): 408-414.

26. Gatenby RA, Gillies RJ (2004) Why do cancers have high aerobic glycolysis?. Nature Reviews Cancer 4(11): 891-899.
27. Kim JW, Dang CV (2006) Cancer's molecular sweet tooth and the Warburg effect. Cancer Research. 66(18): 8927-8930.

28. López-Lázaro M (2008) The warburg effect: why and how do cancer cells activate glycolysis in the presence of oxygen?. Anti-Cancer Agents in Medicinal Chemistry 8(3): 305-312.

29. Bustamante E, Pedersen PL (1977) High aerobic glycolysis of rat hepatoma cells in culture: role of mitochondrial hexokinase. Proceedings of the National Academy of Sciences of the United States of America. 74(9): 3735-3739.

30. Unwin RD, Craven RA, Harnden P, Hanrahan S, Totty $N$, et al. (2003) Proteomic changes in renal cancer and co-ordinate demonstration of both the glycolytic and mitochondrial aspects of the Warburg effect. Proteomics 3(8): 1620-1632.

31. Christofk HR, Vander Heiden MG, Harris MH, Ramanathan A, Gerszten RE, et al. (2008) The M2 splice isoform of pyruvate kinase is important for cancer metabolism and tumour growth. Nature 452(7184): 230-233.

32. Pedersen PL (2007) Warburg, me and Hexokinase 2: Multiple discoveries of key molecular events underlying one of cancers' most common phenotypes, the "Warburg Effect", i.e., elevated glycolysis in the presence of oxygen. Journal of Bioenergetics and Biomembranes. 39(3): 211-222.

33. Pelicano H, Martin DS, Xu RH, Huang P (2006) Glycolysis inhibition for anticancer treatment. Oncogene 25(34): 4633-4646.

34. Clinical trial number NCT00633087 for A Phase I/II Trial of 2-Deoxyglucose (2DG) for the Treatment of Advanced Cancer and Hormone Refractory Prostate Cancer (2-Deoxyglucose).

35. Colen CB (2005) Gene therapy and radiation of malignant glioma by targeting glioma specific lactate transporter. Wayne State University.

36. Colen CB, Seraji-Bozorgzad N, Marples B, Galloway MP, Sloan AE, et al. (2006) Metabolic remodeling of malignant gliomas for enhanced sensitization during radiotherapy: an in vitro study. Neurosurgery. 59(6): 1313-1323. 


\section{International Journal of Biochemistry \& Physiology}

37. Colen CB, Shen Y, Ghoddoussi F, Yu P, Francis TB, et al. (2011) Metabolic targeting of lactate efflux by malignant glioma inhibits invasiveness and induces necrosis: an in vivo study. Neoplasia 13(7): 620-632.

38. Mathupala SP, Colen CB, Parajuli P, Sloan AE (2007) Lactate and malignant tumors: a therapeutic target at the end stage of glycolysis. Journal of Bioenergetics and Biomembranes 39(1): 73-77.

39. Bonnet S, Archer SL, Allalunis-Turner J, Haromy A, Beaulieu C, et al. (2007) A mitochondria-K+ channel axis is suppressed in cancer and its normalization promotes apoptosis and inhibits cancer growth. Cancer Cell 11(1): 37-51.

40. Pan JG, Mak TW (2007) Metabolic targeting as an anticancer strategy: dawn of a new era?. Science's STKE 2007(381): pe14.

41. Klement RJ, Kämmerer U (2011) Is there a role for carbohydrate restriction in the treatment and prevention of cancer?. Nutrition \& Metabolism 8: 75.

42. Volek JS, Fernandez ML, Feinman RD, Phinney SD (2008) Dietary carbohydrate restriction induces a unique metabolic state positively affecting atherogenic dyslipidemia, fatty acid partitioning, and metabolic syndrome. Prog Lipid Res 47(5):307-18.

43. Allen BG, Bhatia SK, Anderson CM, EichenbergerGilmore JM, Sibenaller ZA, et al. (2014) Ketogenic diets as an adjuvant cancer therapy: History and potential mechanism. Redox Biol 2: 963-970.

44. Otto Warburg, Franz Wind, Erwin Negelein (1927) THE METABOLISM OF TUMORS IN THE BODY. J Gen Physiol 8(6): 519-530.

45. Klement RJ (2013) Calorie or carbohydrate restriction? The ketogenic diet as another option for supportive cancer treatment. Oncologist 18(9):1056.

46. Rainer J Klement, Ulrike Kämmerer (2011) Is there a role for carbohydrate restriction in the treatment and prevention of cancer? Nutr Metab (Lond) 8: 75.

47. AM Poff, C Ari, P Arnold, TN Seyfried, DP D'Agostino (2014) Ketone supplementation decreases tumor cell viability and prolongs survival of mice with metastatic cancer. Int J Cancer 135(7): 1711-1720.

48. Weihua Zhou, Purna Mukherjee, Michael A Kiebish, William T Markis, John G Mantis, et al. (2007) The calorically restricted ketogenic diet, an effective alternative therapy for malignant brain cancer. Nutr Metab (Lond) 4: 5.

49. Poff AM, Ari C, Seyfried TN, D'Agostino DP (2013) The ketogenic diet and hyperbaric oxygen therapy prolong survival in mice with systemic metastatic cancer. PLoS One 8(6): e65522.

50. Mavropoulos JC, Buschemeyer WC 3rd, Tewari AK, Rokhfeld D, Pollak M, Zhao Y, et al. (2009) The effects of varying dietary carbohydrate and fat content on survival in a murine LNCaP prostate cancer xenograft model. Cancer Prev Res (Phila). 2(6):557-565.

51. Otto C, Kaemmerer U, Illert B, Muehling B, Pfetzer N, Wittig R, Voelker HU, et al. (2008) Growth of human gastric cancer cells in nude mice is delayed by a ketogenic diet supplemented with omega-3 fatty acids and medium-chain triglycerides. BMC Cancer 8:122.

52. Zuccoli G, Marcello N, Pisanello A, Servadei F, Vaccaro $S$, et al. (2010) Metabolic management of glioblastoma multiforme using standard therapy together with a restricted ketogenic diet: Case Report. Nutr Metab (Lond) 7:33.

53. Nebeling LC, Miraldi F, Shurin SB, Lerner E (1995) Effects of a ketogenic diet on tumor metabolism and nutritional status in pediatric oncology patients: two case reports. J Am Coll Nutr 14(2):202-208.

54. Schmidt M, Pfetzer N, Schwab M, Strauss I, Kämmerer $\mathrm{U}$ (2011) Effects of a ketogenic diet on the quality of life in 16 patients with advanced cancer: A pilot trial. Nutr Metab (Lond) 8(1): 54.

55. Rossi-Fanelli F, Franchi F, Mulieri M, Cangiano C, Cascino A, et al. (1991) Effect of energy substrate manipulation on tumour cell proliferation in parenterally fed cancer patients. Clin Nutr 10(4): 22832.

56. Kenneth Schwartz, Howard T Chang, Michele Nikolai, Joseph Pernicone, Sherman Rhee, et al. (2015) Treatment of glioma patients with ketogenic diets: report of two cases treated with an IRB-approved energy-restricted ketogenic diet protocol and review of the literature. Cancer Metab 3: 3.

57. Bailey Regina. "Cellular Respiration". 


\section{International Journal of Biochemistry \& Physiology}

58. Rich PR (2003) The molecular machinery of Keilin's respiratory chain. Biochemical Society Transactions. 31(Pt 6): 1095-1105.

59. Jane B Reece, Lisa A Urry, Michael L Cain, Steven A Wasserman, Peter V Minorsky, el al. (2010) Campbell Biology Ninth Edition. Pearson Education, Inc. pp. 168.

60. Porter R, Brand M (1995) Mitochondrial proton conductance and $\mathrm{H}+/ \mathrm{O}$ ratio are independent of electron transport rate in isolated hepatocytes. The Biochemical Journal 310(Pt 2): 379-382.
61. Stryer, Lubert (1995) Biochemistry. (Fourth ed.), W H Freeman and Company New York.

62. Thomas N Seyfried, Roberto E Flores, Angela M. Poff, Dominic P. D’Agostino (2014) Cancer as a metabolic disease: implications for novel therapeutics. Carcinogenesis 35(3): 515-527.

63. Marshall, William J, Bangert Stephen K (2008) Clinical biochemistry: metabolic and clinical aspects. Elsevier Health Sciences. pp. 67-80. 